\title{
Alternative Technologies for the Producing Phenol
}

\author{
V. M. Zakoshanskii \\ 4756 Doncaster Court, Long Grove, IL 60047-6929, USA \\ phone: (847)913-5861 \\ fax (847)913-5872 \\ e-mail:vlazak@il allc.com, illa.ru@illallc.com,http://www.illallc.com
}

Received March 25, 2008

This article is withdrawn by the author, must be considered nonexistent and should not be cited. 